\title{
Formation, Kinetics and Control Strategies of Nox Emission in Hydrogen Fueled IC Engine
}

\author{
Abinash Pani \\ Mechanical Engineering Department \\ VSSUT Burla, Odisha
}

\begin{abstract}
With the increase in demand of environmental safety leads to the development of unconventional fuels. Though use of these unconventional fuels like hydrogen etc. heads to low emission, it is associated with shortcomings such as back fire, knocking, and NOx emission. This paper gives you a comprehensive overview on the phenomena of NOx formation, its effect on atmosphere, comparison between the NOx emission of hydrogen based IC engine and conventional fuel IC engine, it's control techniques and their effectiveness. The future research direction on hydrogen sourced IC engines is also presented.
\end{abstract}

Keywords-Hydrogen; NOx; IC engine.

\section{INTRODUCTION}

With an increase in the demand of automobile there is a parallel development of the emission problem and scarcity of conventional fuels like petrol and diesel. Unconventional fuels like bio gas, bio diesel, hydrogen have given hope to overcome that, but the development of these unconventional fuels is only constrained to the theoretical and laboratory research. In recent years, it is demonstrated to have a clear future ahead with slight modification and using various control techniques.

Use of hydrogen as the main fuel is not entirely a new concept. In the 1930s about thousand engines were converted to hydrogen engine [1] in England and Germany, but after that hydrogen was only used in laboratory research owing to lack of interest of companies. In the 19th and 20th centuries the application of hydrogen again came into picture due to the environmental effect and scarcity of gasoline and diesel fuel. The application and practical significance of development of hydrogen energy are dealt in [2], [3]. With the increase in practical applications of the hydrogen as fuel problems such as knocking, misfire, loud noise and back fire were noticed.

A. Hydrogen as fuel in IC engines

Hydrogen having properties such as high flammability range, low ignition energy (as stated in Table 1) makes it useful in the SI engine [4], [5]. But due to its high self-ignition temperature it cannot be ignited only by the compression. However, by means of some external source of ignition like glow plug [6], [7] the hydrogen as a fuel for CI engine.

Hydrogen can be used as the fuel in the small power diesel engine in the agricultural sector [8]. The drawbacks like misfire; backfire and knocking are significant in diminishing the engine performance. Uses of timed manifold injection system [39], port injection, flame trap, cold spark plug [7] are possible solutions to the above problem. Hydrogen IC engines emit very low $\mathrm{CH}$ except the $\mathrm{CH}$ emission caused by the engine lubrication oil and the diesel used in the C.I. engine. But it has one drawback of high rate of NOX emission compared to the gasoline [9].

\section{II. $\mathrm{NO}_{\mathrm{X}}$ EMISSION}

The compounds like $\mathrm{NO}$ (nitric oxide), $\mathrm{NO}_{2}$ (nitrogen oxide) $\mathrm{N}_{2} \mathrm{O}$ (nitrous oxide) are

known as the NOx. These are among the primary pollutants produced from the vehicles. As these oxides get destroyed immediately when released to air these are termed as NOx.

Formation of NOx normally takes place in high temperature of about $2800 \mathrm{~K}$. Thus, the main production of NOx takes place in the IC engines as they develop more amount of heat during the power stroke.

Mainly nitrogen oxides get produced from the reaction taking place inside the cylinder between the nitrogen and oxygen. The main source of nitrogen in case of gasoline or diesel fueled engine are the carbon compounds which have nitrogen in their structures like Amines, Pyridines, Quinoline $(0.5-2 \%)$ having chemical structures as given in the Fig. 1. These compounds if present in the fuel will produce nitrogen which will react with the oxygen to produce oxides of nitrogen.

But in case of hydrogen fueled engine though there is no $\mathrm{CH}$ fuels (except engine oil) containing nitrogen the major amount nitrogen is from the air itself, which in high temperature is likely to give rise nitrogen oxides.

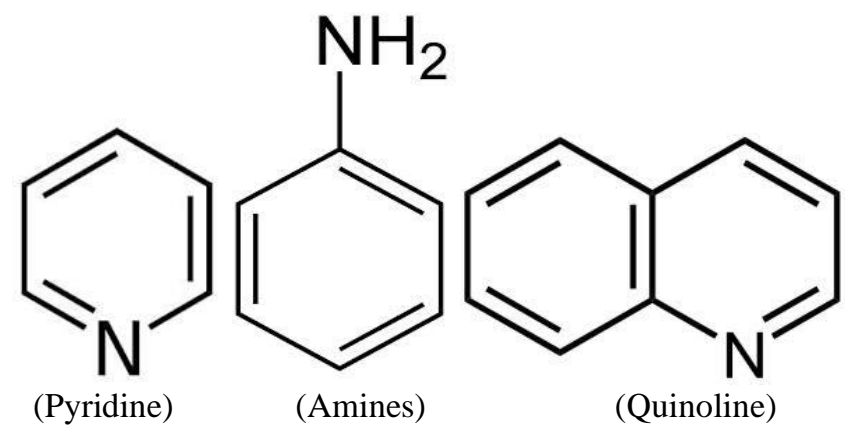

Fig. 1. Chemical Structure of Pyridine Amines, Quinoline 


\begin{tabular}{|l|l|l|l|}
\hline Property & Hydrogen & Methane & Gasoline \\
\hline Molecular weight & 2.016 & 16.043 & 107 \\
\hline Density of gas, $\mathrm{g} \mathrm{m}^{-3}$ & 83.764 & 651.19 & 4400 \\
\hline $\begin{array}{l}\text { Specific heat capacity at NTP, } \mathrm{J} \mathrm{g}^{-1} \\
\mathrm{~K}^{-1}\end{array}$ & 14.89 & 2.22 & 1.62 \\
\hline Limit of flammability in air \% vol & 4.0 to 75.0 & 5.3 to 15.0 & 1.0 to 7.6 \\
\hline Minimum ignition energy in air in MJ & 0.02 & 0.29 & 0.24 \\
\hline Auto ignition temperature(K) & 858 & 813 & 501 to 744 \\
\hline $\begin{array}{l}\text { Limit of flammability (equivalence } \\
\text { ratio) }\end{array}$ & $0.1-7.1$ & $0.53-1.7$ & $0.7-3.8$ \\
\hline Quenching gap in NTP air, cm & 0.064 & 0.203 & 0.2 \\
\hline Burning velocity in NTP air, $\mathrm{cm} \mathrm{s}^{-1}$ & 265 to 325 & 37 to 45 & 37 to 43 \\
\hline
\end{tabular}

\section{A. Effect of $\mathrm{NO}_{X}$ emission}

Pollutants like NOx affect the atmosphere mainly in the form of acid rains, ozone formation, and smog formation. With the addition of NOx with rain it gets converted into dangerous acid rain. Formation of ozone molecules from the reaction of volatile organic compounds leads to the lung diseases and health related issues.

In the stratosphere, the decrement of ozone layer that absorbs the ultraviolet rays is helped by the oxides of nitrogen. Different toxic compounds like nitrosamines, nitroarenes are formed due to the reactions between NOx and organic compounds. These lead to the biological mutation.

According to a Report [65] India is $4^{\text {th }}$ among 128 countries in the NOx emission, with 300,680 thousand metric tons of $\mathrm{CO}_{2}$ equivalent compared to 456,210 thousand metric tons of $\mathrm{CO}_{2}$ equivalent of United States, which is $52 \%$ higher than of India. Fig. 2 provides a graphical representation of the amount of NOx emission [66]. Chaichan, Abass [9] have studied the NOx emission for different fuels like CNG, gasoline, hydrogen at a given compression ratio (CR).

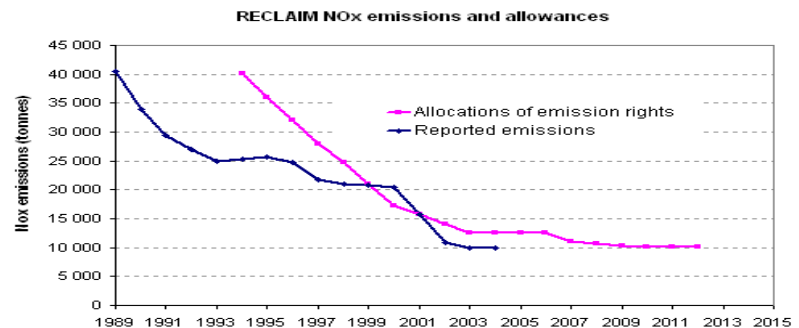

Fig. 4. NOx emission in different year according to report [66].

\section{FORMATION OF NOX}

Basically, the formation of NOx is a very complex mechanism and many researchers have studied on the kinetics of NOx formation [10], [11]. NOx formation normally takes place in five processes [12] such as thermal -Zeldovic mechanism, Fenimore prompt mechanism, $\mathrm{N}_{2} \mathrm{O}$ intermediate mechanism, NNH mechanism, and fuel NOx mechanism.

They have found that for different CRs the NOx concentration is the highest for the hydrogen fueled SI engine followed by $\mathrm{CNG}$, gasoline and natural gas. The results are shown in the Fig. 3 and 4. Due to less time for flame propagation, hydrogen easily burns, which helps in producing more NOx.

Thermal NOx is observed to be predominant compared to the others and are produced in high range of equivalence ratio. Fenimore mechanism is suitable to produce NOx in the rich concentration whereas the use of lean fuel at low temperature leads to the $\mathrm{N}_{2} \mathrm{O}$ intermediate mechanism. Miller and Bowman [11] have found that for equivalent ratio $(\varnothing)$ between $0.8-1.0$, thermal NOx is predominant. For $\emptyset<0.8, \mathrm{~N}_{2} \mathrm{O}$ intermediate is the cause of NOx formation. For $\emptyset>1.2$, prompt NOx is predominant over other NOx

A. Thermal NOx

Thermal NOx is one of the main constituents for the

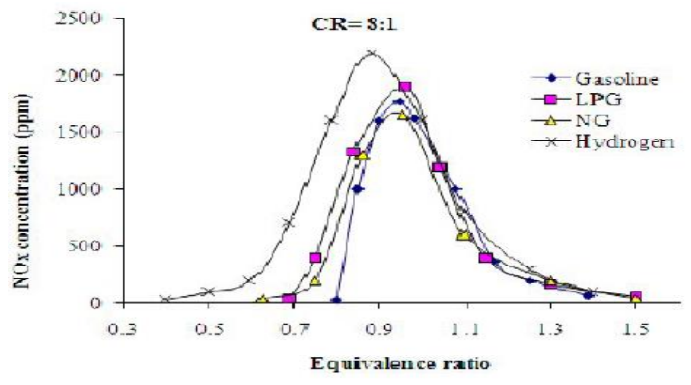

Fig. 3. Effect of equivalent ratio on NOx concentration in different fuels for CR suitable for Gasoline engine (8:1) [66].

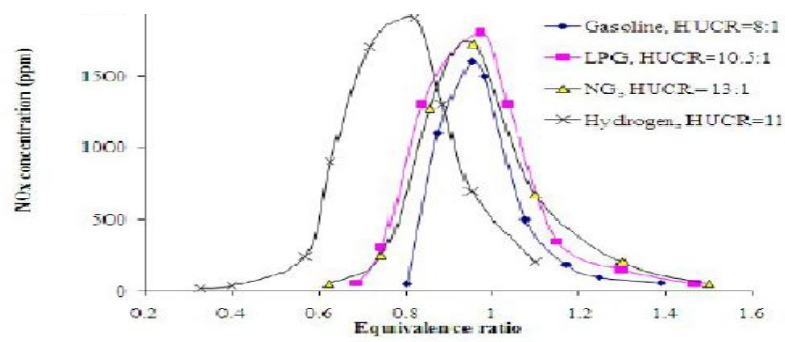

Fig. 2. Effect of equivalent ratio on NOx concentration in different fuels for CR suitable for themselves[66].

formation of NOx. Basically, formation of NOx takes place by the Zeldovic and extended Zeldovic mechanism [13] as

$\mathrm{O}+\mathrm{N}_{2} \leftrightarrow \mathrm{NO}+\mathrm{N}$
$\mathrm{N}+\mathrm{O}_{2} \leftrightarrow \mathrm{NO}+\mathrm{O}$
$\mathrm{N}+\mathrm{OH} \leftrightarrow \mathrm{NO}+\mathrm{H}$ 
Equations (1) and (2) are the Zeldovic mechanism for the formation of NOx and (3) is the extended Zeldovic mechanism proposed by Lavoie et al. [13]. As all the three reactions take place in the presence of the $\mathrm{O}, \mathrm{OH}$ and $\mathrm{O}_{2}$ radical, the fuel burning reactions have significant contribution towards these. But with the assumption made by Zeldovic that NOx formation takes place after complete burning of the fuel the two reactions can be uncoupled [11], [12]. It is assumed that after long time $\mathrm{N}_{2}, \mathrm{O}_{2}, \mathrm{O}, \mathrm{OH}$ and $\mathrm{N}$ remain at their respective equilibrium and steady values. At that time, the approximate NO concentration can be measured.

An important justification of this assumption as provided in [13] that the combustion taking place inside the cylinder has high pressure leading to very small residence time in the flame reaction zone and the highest temperature suitable for the NOx formation is achieved when the burned gas gets compressed, that is just after the ignition. So, it is applicable to decouple the reactions to measure the approximate NO concentration.

According to [13], the simple equation of equilibrium regarding the formation of $\mathrm{NO}$ can be written as

$$
\frac{d[\mathrm{NO}]}{d t}=\mathrm{k}_{1}^{+}\left[\mathrm{N}_{2}\right][\mathrm{O}]+\mathrm{k}_{2}^{+}[\mathrm{N}]\left[\mathrm{O}_{2}\right]+\mathrm{k}_{3}^{+}[\mathrm{N}][\mathrm{OH}]-\mathrm{k}_{1}^{-}[\mathrm{NO}][\mathrm{N}]
$$$$
-\mathrm{k}_{2}^{-}[\mathrm{NO}][\mathrm{O}]-\mathrm{k}_{3}^{-}[\mathrm{NO}][\mathrm{H}]
$$

With the above stated assumption that $\mathrm{N}_{2}$ concentration is in steady state and all other concentrations are in equilibrium state the equation (4) can be reduced to

$\frac{d[\mathrm{NO}]}{d t}=2 \mathrm{R}_{1} \frac{1-\left([\mathrm{NO}]\left[\mathrm{NO}_{\mathrm{e}}\right)^{2}\right.}{1+\left([\mathrm{NO}][\mathrm{NO}]_{\mathrm{e}}\right) \mathrm{R}_{1} /\left(\mathrm{R}_{2}+\mathrm{R}_{3}\right)}$

From (5) the difference of $R_{1} / R_{2}, R_{1} / R_{2}+R_{3}$ suggests the importance of (3).

If $[\mathrm{NO}] /[\mathrm{NO}]_{\mathrm{e}}<<1(5)$ is reduced to $(6)$

$\frac{d[\mathrm{NO}]}{d t}=2 \mathrm{R}_{1}$

$\mathrm{R}_{1}=\mathrm{k}_{1}^{+}\left[\mathrm{N}_{2}\right]_{\mathrm{e}}[\mathrm{O}]_{\mathrm{e}}=\mathrm{k}_{1}^{-}[\mathrm{NO}]_{\mathrm{e}}[\mathrm{N}]_{\mathrm{e}}$

$\mathrm{R}_{2}=\mathrm{k}_{2}^{+}[\mathrm{N}]_{\mathrm{e}}\left[\mathrm{O}_{2}\right]_{\mathrm{e}}=\mathrm{k}_{2}^{-}[\mathrm{NO}]_{\mathrm{e}}[\mathrm{O}]_{\mathrm{e}}$

$\mathrm{R}_{3}=\mathrm{k}_{3}^{+}[\mathrm{N}]_{\mathrm{e}}[\mathrm{OH}]_{\mathrm{e}}=\mathrm{k}_{3}^{-}[\mathrm{NO}]_{\mathrm{e}}[\mathrm{H}]_{\mathrm{e}}$

$\mathrm{k}_{1}^{+} \mathrm{k}_{1}^{-} \mathrm{k}_{2}^{+} \mathrm{k}_{2}^{-} \mathrm{k}_{3}^{+} \mathrm{k}_{3}^{-}$are respective equilibrium constant used in (7), (8) and (9) The numerical values of these constants at the corresponding range of the temperatures are listed in Table 2. The equilibrium constants are experimentally studied by Miller et al. [11] and Heywood [13].

\section{TABLE II. RATE CONSTANT}

\begin{tabular}{|c|c|c|}
\hline Constant & Rate constant $\left(\mathrm{cm}^{3} / \mathbf{m o l} . \mathbf{s}\right)$ & Temperature range, $\mathbf{K}$ \\
\hline $\mathrm{k}_{1}^{+}$ & $7.6 \times 10^{13} \exp [-38,000 / \mathrm{T}]$ & $2000-5000$ \\
\hline $\mathrm{k}_{1}^{-}$ & $1.6 \times 10^{13}$ & $300-5000$ \\
\hline $\mathrm{k}_{2}^{+}$ & $6.4 \times 10^{9} \mathrm{~T} \exp [-3150 / \mathrm{T}]$ & $300-3000$ \\
\hline $\mathrm{k}_{2}^{-}$ & $1.5 \times 10^{9} \mathrm{~T} \exp [-19500 / \mathrm{T}]$ & $1000-3000$ \\
\hline $\mathrm{k}_{3}^{+}$ & $4.1 \times 10^{13}$ & $300-2500$ \\
\hline $\mathrm{k}_{3}^{-}$ & $2.0 \times 10^{14} \exp [-23,650 / \mathrm{T}]$ & $2200-4500$ \\
\hline
\end{tabular}

B. Prompt NOx

It is studied in [14] the formation of nitric oxide takes place rapidly from the nitrogen during the time of flame zones of laminar premixed flames [15]. Within the flame zone the assumption of equilibrium is not always valid. High concentration of the oxygen at the period of reaction in the flame zones increases the amount of NO concentration. This formation of $\mathrm{NO}$ due to the participation of excess $\mathrm{O}$ is the basis of prompt reaction phenomena [12].

The reaction in [16]-[25] suggests that more amount of hydrocarbon radicals react with molecular nitrogen to form the Amine and Cyano compounds, which then get converted into their respective intermediate compounds leaving behind $\mathrm{NO}$ as [11], [12]

$$
\begin{aligned}
& \mathrm{CH}+\mathrm{N}_{2} \leftrightarrow \mathrm{HCN}+\mathrm{N} \\
& \mathrm{C}+\mathrm{N}_{2} \leftrightarrow \mathrm{CN}+\mathrm{N} \\
& \mathrm{HCN}+\mathrm{O} \leftrightarrow \mathrm{NCO}+\mathrm{H} \\
& \mathrm{NCO}+\mathrm{H} \leftrightarrow \mathrm{NH}+\mathrm{CO} \\
& \mathrm{NH}+\mathrm{H} \leftrightarrow \mathrm{N}+\mathrm{H}_{2} \\
& \mathrm{~N}+\mathrm{OH} \leftrightarrow \mathrm{NO}+\mathrm{H}
\end{aligned}
$$

The steps in (10) to (15) are for equivalent ratio less than 1.2. If it exceeds more than 1.2 then formation of $\mathrm{NO}$ becomes much more complex as different paths for formation of NOx open [12].

\section{C. $\mathrm{N}_{2} \mathrm{O}$ intermediate mechanism}

In the region of low temperature and low equivalent ratio the formation of $\mathrm{NO}$ is mainly through the formation $\mathrm{N}_{2} \mathrm{O}$ intermediate mechanism as

$\mathrm{O}+\mathrm{N}_{2}+\mathrm{M} \leftrightarrow \mathrm{N}_{2} \mathrm{O}+\mathrm{M}$

$\mathrm{H}+\mathrm{N}_{2} \mathrm{O} \leftrightarrow \mathrm{NO}+\mathrm{NH}$

$\mathrm{O}+\mathrm{N}_{2} \mathrm{O} \leftrightarrow \mathrm{NO}+\mathrm{NO}$

\section{Fuel NOx}

Formation of the NO from the fuel takes place through a chain reaction through which firstly the bounded nitrogen is transformed into the $\mathrm{HCN}$ or $\mathrm{NH}_{3}$, and then it is followed by the reaction steps of prompt NOx [11].

E. NNH Reaction

As explained in $\mathrm{N}_{2} \mathrm{O}$ intermediate mechanism there are four possible reactions between $\mathrm{H}$ and $\mathrm{N}_{2} \mathrm{O}$ [26] as mentioned in (19) to (22).

$\mathrm{H}+\mathrm{N}_{2} \mathrm{O} \leftrightarrow \mathrm{NO}+\mathrm{NH}$

$\mathrm{H}+\mathrm{N}_{2} \mathrm{O} \leftrightarrow \mathrm{HNNO}$

$\mathrm{H}+\mathrm{N}_{2} \mathrm{O} \leftrightarrow \mathrm{N}_{2}+\mathrm{HO}$

$\mathrm{H}+\mathrm{N}_{2} \mathrm{O} \leftrightarrow \mathrm{NNH}+\mathrm{O}$

Bozzeli has suggested that the formation of $\mathrm{NNH}$ radical from the reaction of $\mathrm{N}_{2}$ and $\mathrm{H}$ as

$$
\mathrm{N}_{2}+\mathrm{H} \leftrightarrow \mathrm{NNH}
$$

This NNH intermediates oxidize and give rise to $\mathrm{NO}$ as in (24).

$$
\mathrm{NNH}+\mathrm{O} \leftrightarrow \mathrm{NO}+\mathrm{NH}
$$

Harrington et al. [27] have found that NO is formed through this mechanism if cool, fuel rich, low pressure, premixed hydrogen/air flames are used. Konnov [28], [29] have also observed that the NNH mechanism is significant for all temperature with a very small residence time. At temperature $2100 \mathrm{~K}$, thermal NOx becomes dominant after one millisecond. At low temperature of $1500 \mathrm{~K}$ and moderately high temperature of $1900 \mathrm{~K}$ the $\mathrm{NNH}$ mechanism is more for all residence time [28]- [30].

Miler et al. [31] have further studied the chemical kinetic models and relationship of NNH mechanism with thermal NOx and have evaluated heat and life time of NNH.

\section{F. $\mathrm{NO}_{2}$ Formation}

The main cause of acid rain is the nitrous oxide $\left(\mathrm{NO}_{2}\right)$ that forms in the atmosphere from NO. But in the engine, itself the formation and destruction of $\mathrm{NO}_{2}$ takes place

$\mathrm{NO}+\mathrm{HO}_{2} \leftrightarrow \mathrm{NO}_{2}+\mathrm{OH}$ (Formation) 
$\mathrm{NO}_{2}+\mathrm{H} \leftrightarrow \mathrm{NO}+\mathrm{OH}$ (Destruction)

$\mathrm{NO}_{2}+\mathrm{O} \leftrightarrow \mathrm{NO}+\mathrm{O}_{2}$ (Destruction)

$\mathrm{HO}_{2}$ is formed by the reaction

$$
\mathrm{H}+\mathrm{O}_{2}+\mathrm{M} \leftrightarrow \mathrm{HO}_{2}+\mathrm{M}
$$

$\mathrm{HO}_{2}$ formation is more in the low temperature region and hence it increases the rate of formation of $\mathrm{NO}_{2}$ in that region. The $\mathrm{NO}_{2}$ destruction is active at high temperature region. It has been observed that quenching at low load increases the ratio $\left[\mathrm{NO}_{2}\right] /[\mathrm{NOx}]$ compared to the quenching at high load. A detailed explanation of the $\left[\mathrm{NO}_{2}\right] /[\mathrm{NOx}]$ is given in [32].

In case of fuel having no carbon compounds such as hydrogen fuel, formation of $\mathrm{NOx}$ is mainly based on the kinetics of thermal NOx i.e. extended Zeldovic mechanism. Others like prompt, $\mathrm{N}_{2} \mathrm{O}$ intermediate mechanism and $\mathrm{NNH}$ mechanism though have significant effect in concentration, and it can be neglected by using required equivalent ratio, temperature and pressure.

\section{FACTORS AFFECTING NOX CONCENTRATION IN HYDROGEN IC ENGINE}

It is evident from the literature that the NOx amount mainly depends on main factors such as temperature, residence time, compression ratio and equivalent ratio. As discussed earlier the chemical kinetics of NOx formation is mainly favorable when the temperature is high, that is the temperature of the burned gas is high. Residence time can be defined as the time taken for the reaction to complete. The NOx concentration increases with a decrease in residence time due to an increase in flame propagation speed and reaction speed.

\section{A. Spark timing}

It has been found from literature and experimental values that spark timing has a significant effect on the NOx emission. Advancing the timing such that combustion takes place earlier increases the peak cylinder pressure and moves the peak pressure closer to the top dead centre. This increase burned gas temperature hence initiates formation of more NOx. The technique of retarding the spark timing to decrease the formation of NOx has been reported in [5], [33] and [34].

Subramanian et al. [33] have found that with fuel flow rate (FFR) of $0.68 \mathrm{~kg} / \mathrm{h}$ and $0.76 \mathrm{~kg} / \mathrm{h}$ the retardation of spark timing helps in decreasing the NOx concentration (Fig 5). They have demonstrated that NOx concentration can be minimized significantly in a fuel of low equivalent ratio by retarding the spark timing at the expense of brake thermal efficiency.



Fig. 5. Variation of $\mathrm{NO}(\mathrm{ppm})$ with spark timing $\left({ }^{\circ} \mathrm{CA}\right)$.

\section{B. Equivalent ratio}

It is observed from [13] that the concentration NOx decreases as fuel becomes lean. This happens mainly due to the low fuel amount compared to the oxygen, thus decreasing the burned gas temperature that inhibits the formation of NOx.

Also, it has been noticed that with increase in the equivalent ratio above a limit decreases the NOx concentration, as there is insufficient oxygen for the combustion, thus decreasing the effective burned gas temperature.

Subramanian et al. [33], Homan et al. [34], Das et al. [35] and Wallner et al. [36] have reported similar experimental observations.

Referring to Fig. 6 it is observed [33] that for an equivalent

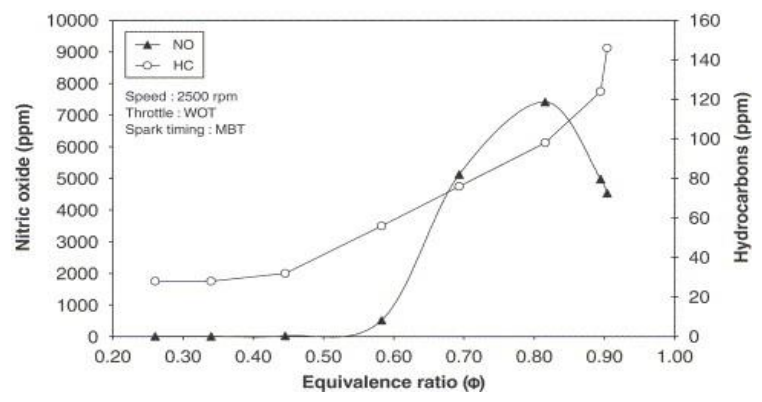

Fig. 6. Variation of Nitric Oxide (ppm) with Equivalent ratio.

ratio of 0.55 , the $\mathrm{NOx}$ emission is negligible and its concentration attends peak at an equivalent ratio of 0.8 for a fluid flow rate of $7800 \mathrm{ppm}$. Increasing $\emptyset$ further the plot shows a decreasing trend of NOx concentration which is similar to the observation reported in [13].

Mathur and Khajuria [37] have studied the relationship between the amounts of NO emission in a hydrogen fueled SI engine and speed at four different compression ratios.



Fig. 7. Variation of NOx amount with equivalent ratio at 1600 rpm and 6 compression ratios. 
Das et al. [38], [39] also have studied the effect of different CR on NOx concentration at a constant speed of $1600 \mathrm{rpm}$ in a SI engine. From Fig. 7, it is observed that with an increase in compression ratio the NOx concentration is increased due to high temperature condition and high flame speed.

\section{Injection timing}

Different studies [40]- [49] on the effect of injection timing on the NOx concentration indicate relative complex behavior of the injection timing.

Homan et al. [40] in their research work on a ASTM CFR engine with a LIRIAM scheme (late ignition, rapid ignition and mixing) have studied the effect of different injection timing for a constant speed of $1200 \mathrm{rpm}$ and a spark timing of $5^{\circ}$ BTC. They have found out an effect of stratification [44], [45] on the mixture of hydrogen and oxygen that increases the NOx concentration reducing the homogeneity of the mixture. Results shown in the Fig. 8 provide three distinct observations (i).at early injection (before injection timing $40^{\circ}$ BTC) gives an additional mixing time hence reducing the stratification amount thus reducing the NOx emission, (ii) for late injection (later than $30^{\circ}$ BTC) the maximum hydrogen burning occurs in the local equivalent ratio greater than 0.8 , thus reducing the NOx and (iii) for the scheme designed for the late injection at $6^{\circ}$ BTC the NOx emission for premixed fuel mixture is still higher.

White et al. [43] in their paper have discussed the effect of retarding SOI (Start of Injection Time) to the heterogeneity and its different effects for two range of equivalent ratio one below NOx limited equivalent ratio and another one above the limited equivalent ratio. For the region of equivalent ratio below limited value shows an increase in the NOx concentration with an increase in heterogeneity of the mixture and an opposite trend for the fuel mixture of equivalent ratio more than limited value.

It is observed in [41] that for a lean operation $\lambda>2$ the late injection timing increases the NOx concentration in the exhaust. These results are found out to be similar to the results reported by White et al. [43].

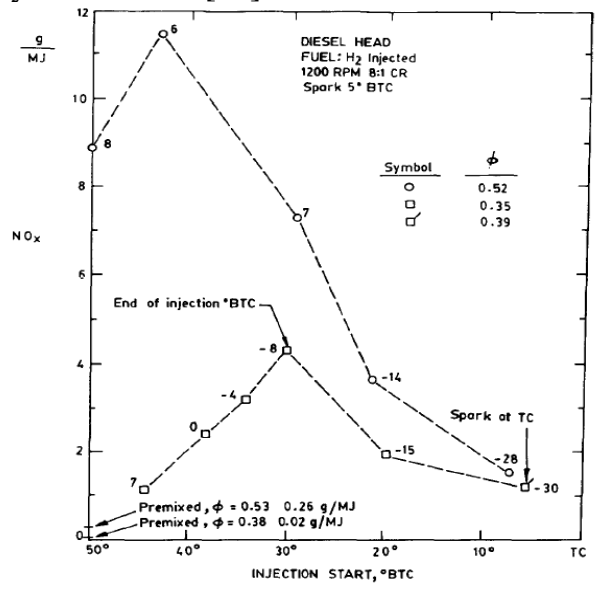

Fig. 8. Relationship between NOx emission and injection start timing $\left({ }^{\circ} \mathrm{BTC}\right)$.

Burned gas fraction acts as diluents and reduces the peak temperature of the reaction, thus inhibiting production of NOx. Humidity [46] also leads to reduction of NOx emission, as increase in humidity reduces the overall temperature inside the chamber. Ghazzi et al. [47] have studied the effect of combustion duration on NOx emission and have found out that for prolonged combustion duration there is a reduction in the NOx emission. They have compared the results of combustion duration to the NOx emission for different fuels such as neat hydrogen, $70 \% \mathrm{CH}_{4}+30 \% \mathrm{H}_{2}$, only $\mathrm{CH}_{4}$ and only $\mathrm{CO}$. The results are shown in the Fig. 9. They have concluded that for low NOx emission with high power production efficiency, lean mixture with high flame propagation speed is suitable.

The effect of compression ratio on NOx emission in a hydrogen fueled SI engine is studied in [48]. Fig. 10 shows the graph between the compression ratio and equivalent ratio and NOx amount. For an equivalence ratio less than 0.8 , it is observed that increase in compression ratio leads to an increase in the NOx emission due to high combustion temperature with abundance of oxygen. But the behavior of NOx emission with compression ratio for the equivalence ratio greater than 0.8 is different, as amount of NOx decreases with increase in the compression ratio due to a decrease in amount of available oxygen.

Few researchers have investigated on the effect of change in load and speed on NOx emission. Hua et al. [64] have studied the effect of change in speed and load on thermal efficiency and

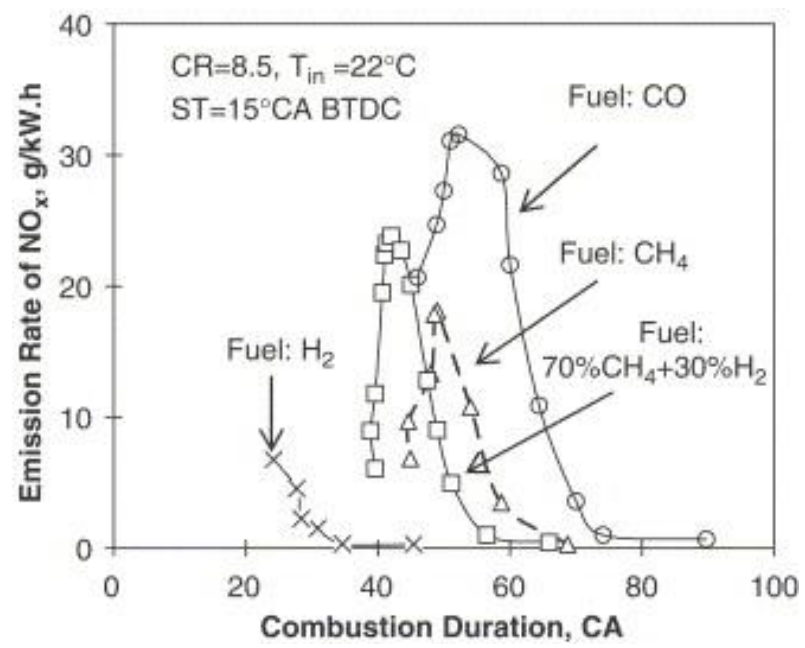

Fig. 9. Relationship between emission rates (g/kW.h) of NOx with Combustion Duration (CA)

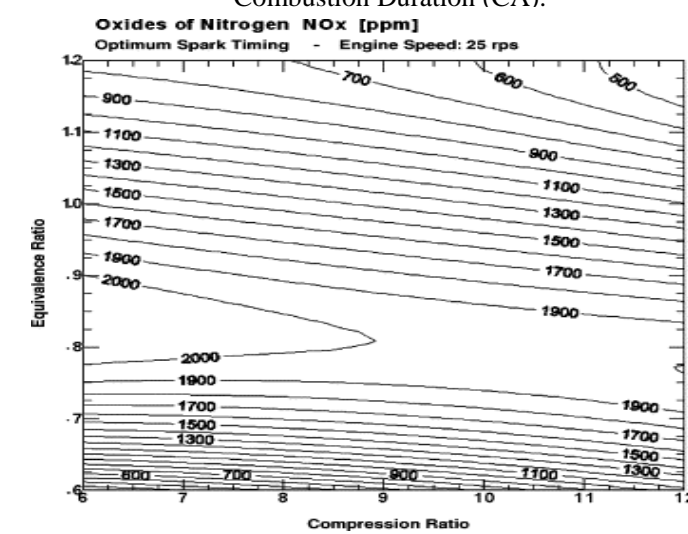

Fig. 10. Variation of NOx amount at different Equivalent ratio and Compression ratio. 




Fig. 11. Variation of NOx emission with degree of throttle and engine speed.

NOx emission. They have observed (Fig. 11) that increase in speed leads to a decrease in NOx emission, as it decreases the temperature inside the combustion chamber.

\section{CONTROL TECHNIQUES}

During the progress in automobile industry importance has also given to reduce the detrimental effects of automobiles. Development of bio diesel, biogas, and hydrogen fuel has led to the solution of ever increasing carbon pollutants, though these are yet to be completely removed. In recent years researchers are working to decrease the pollutants like NOx using techniques such as EGR, spark timing adjustment, catalytic converter etc.

In this section, the development and application on different controlled techniques reported in the literature are outlined.

\section{A. Lean Operation}

One of the most effective and simple techniques used for the reduction of NOx emission is the use of lean fuel mixture. As discussed before, there are evidences that with the use of lean hydrogen fuel substantial reduction of NOx can be achieved. When hydrogen fuel is used with an equivalent ratio less than 0.5 the peak temperature that is developed inside the cylinder decreases due to less combustion, which in fact reduces the overall NOx emission. So, use of lean fuel with wide open throttle is found out to be an effective technique for the NOx control, but as the load in the engine increases, it requires rich fuel mixtures (lean of stoichiometric), due to which the peak combustion temperature increases and it causes a sharp increase in NOx amount when equivalent ratio crosses its threshold value. At that time NOx emission is greater than the gasoline operated engine. Effectiveness of using three ways catalytic converter is less when it is used with lean burn strategy compared to the other developed techniques such as EGR and water injection.

\section{B. Effects of Diluents}

Use of diluents with the intake charge has been found out to be an effective method for the reduction of NOx in IC engines.
Das et al. [49] have compared the effect of different diluents on the emission characteristics of hydrogen fueled diesel engine. For this purpose, they have used a single cylinder, four stroke , water cooled $4 \mathrm{~kW}$ diesel engine that was modified to use hydrogen fuel. Neat hydrogen, hydrogen with helium, hydrogen with nitrogen, and hydrogen with water $(10 \%, 20 \%$, and $30 \%$ diluents res.) have been used as fuels and the emission characteristics have been measured and compared. When they have employed helium as diluents they have observed that with increase in helium concentration reduction in NOx emission takes place but with expense of thermal efficiency and power output [50].

But for the case of nitrogen as diluents, NOx emission is found to be more when the added nitrogen diluents are small in percentage $(10 \%)$. But reduction of NOx is observed for a higher concentration of nitrogen diluents $(20 \%, 30 \%)$. The performance and power output are found out to be better than that of, when helium is used as diluents. Thirdly they have found out that the addition of water in the charge most suitable for reduction of NOx compared to the other diluents, and has high performance characteristics compared to other diluents.

Researchers [51], [52] and [53] have used water injection as effective techniques in the reduction of the NOx. Subramanian et al. [53] have studied on the effect of water injection on the hydrogen fuelled SI engine and its advantages and disadvantages. They observed that it is more practical to use water injection technique compared to the spark timing adjustment as later one leads to back firing. A reduction of $70 \%$ to $80 \%$ of $\mathrm{NO}$ is noticed for a maximum water flow rate of $6 \mathrm{~kg} / \mathrm{h}$. Water injection techniques leads to smoothness during combustion and constant IMEP with no fluctuation and hence beneficial. Water injection technique has high efficiency compared to that of gas diluents.

Nande et al. [54] have found that using a single cylinder, 4 valves pent roof combustion chamber SI engine, water injection technique is more effective than spark retarding technique for the control of NOx emission. In their experiment water is injected at a constant pressure of $50 \mathrm{psi}$ and at $360^{\circ} \mathrm{CA}$ after the SOI timing. Gadallah et al. [55] have shown that the reduction of NOx emission largely depends on the injected water pressure and injection timing. They have concluded that water injection during the later stage of compression stroke is more effective compared to the water injected during expansion stroke as it improves the thermal efficiency and reduces the NOx emission.

Adnan et al. [51] have studied the effect of water injection timing on the NOx reduction in a hydrogen fueled YANMAR C.I. engine which utilizes the mechanically actuated fuel injection system. Water is injected at a constant pressure of 2 bar with start of injection in the range of $20^{\circ} \mathrm{BTDC}$ to $20^{\circ} \mathrm{ATDC}$ and injection duration of $20^{\circ}$ or $40^{\circ} \mathrm{CA}$. They have noticed that maximum $\mathrm{NOx}$ reduction has taken place at water injection timing of $0^{\circ} \mathrm{CA}$ and duration of $40^{\circ} \mathrm{CA}$.

\section{Exhaust Gas Recirculation (EGR)Technique}

One of the widely used techniques for the reduction of NOx without affecting the engine performance is exhaust gas recirculation process. Normally exhaust gas contains low oxygen and burned fuel gas that have both dilution and thermal effects, when added to the inlet charge it acts as a heat sink lowering the combustion temperature thus decreasing the NOx 
concentration. EGR leads to engine wear, clogging of combustion chamber and fouled air intake system. To circumvent these, necessary steps like cooling and filtering and proper controlling of the exhaust gas should be carried out. Amount of EGR is expressed in terms of percentage as,

$\% \mathrm{EGR}=\left(\frac{\mathrm{v}_{\mathrm{EGR}}}{\mathrm{v}_{\mathrm{EGR}}+\mathrm{v}_{\text {fuel }}+\mathrm{v}_{\mathrm{AIR}}}\right) \times 100$

Safari et al. [56] have used the experimental data to calibrate a kinetic model using 3 different zones unburned, flame zones and burned zones. They have compared the reduction in NOx emission using lean burn $(\varnothing=0.88$, EGR $=8 \%)$, hot EGR $\left(110^{\circ} \mathrm{C}\right)$ and cooled EGR. Water is present in hot EGR where as in cooled dry strategy the EGR is cooled and discharged using condensate discharger.

Their findings are plotted in Fig. 12 which shows that for less than $26 \%$ percentage EGR and $\emptyset$ greater than 0.65 there is a significant difference between EGR strategies to the lean burn strategy. The reduction in NOx emission is more with hot EGR strategy compared to the cooled EGR. This is mainly due to the presence of water vapors that increase the specific heat capacity, causing a reduction in mean and maximum combustion temperature, which is the cause of NOx emission.

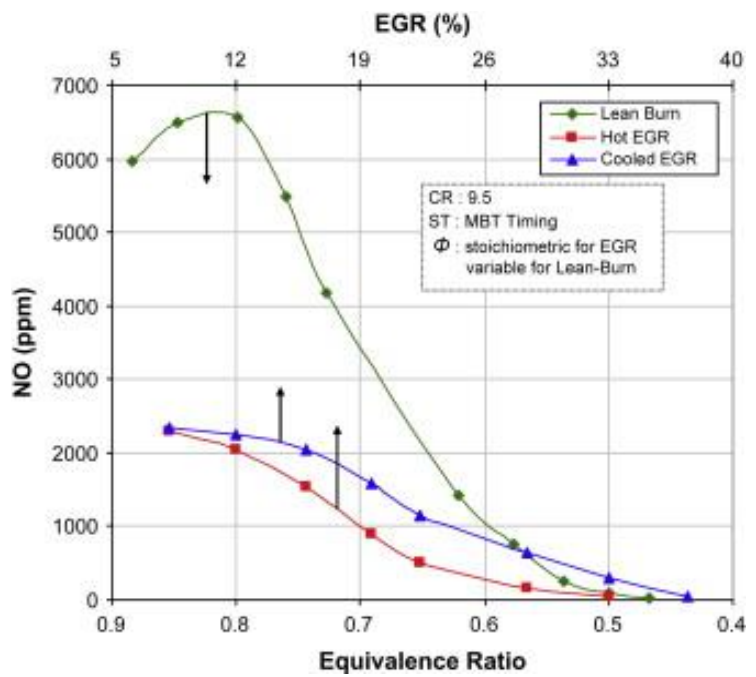

Fig. 12. Comparison of reduction in NOx (ppm) emission with different inlet supply such as lean burn, hot EGR, cooled EGR.

They have also made a comparative performance study on the power output and specific NOx emission and the results are presented in Fig. 13. They have found that the engine with cooled EGR has more power output compared to the engine with hot EGR, as volumetric efficiency of hot EGR is lower compared to the other one. Thermal efficiency is also observed to be more for cooled EGR technique compared to hot EGR.

Their model predicted $33 \%$ and $28 \%$ of cooled EGR and hot EGR respectively for maximum indicated thermal efficiency. These results are also comparable to the ones reported in [57], [58], and [15]. They have concluded from the given kinetic model, that reduction in the NOx can be achieved with lower amount of hot EGR compared to the cooled EGR, though the loss in power output is higher for the hot EGR.

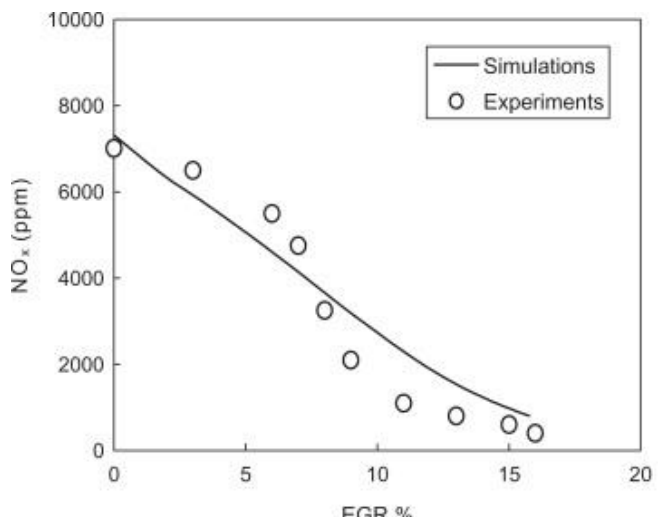

Fig. 13. Comparison of theoretical variation of NOx emission with EGR flow between experimental and simulation results

Heffel [59], [60] has compared the effect of lean burn strategy to the EGR strategy using a hydrogen fueled engine of four cylinders, 2 liters, Ford ZETEC engine with compression ratio $12: 1$. He has used lean burn hydrogen $\left(14 \% \mathrm{H}_{2}, 86 \%\right.$ Air $)$ and EGR diluted hydrogen $\left(14 \% \mathrm{H}_{2}, 34 \%\right.$ air, 52\% EGR) as fuels and has compared the NOx emission and power output. He has noticed that with an increase in EGR percentage, there is a fall in power output and thermodynamic efficiency. He has also noticed that the maximum torque produced from lean burn is $94 \mathrm{Nm}$ higher than torque produced from EGR diluted fuel i.e. $87 \mathrm{Nm}$. But the reduction in NOx emission at that point is observed to be higher for EGR diluted fuel compared to the lean burn fuel. So, an important conclusion is made that for low NOx emission as constraint, the torque output of the engine running in lean burn fuel is significantly reduced. But for the EGR diluted Fuel, NOx output is always low hence for all EGR condition higher torque can be produced. It is evident from the experiment that for near zero NOx emission the torque output of EGR diluted fuel $(87 \mathrm{Nm})$, which is more compared to the lean burn fuel (effectively $68 \mathrm{Nm}$ ). The comparative results are shown in the Fig. 14.

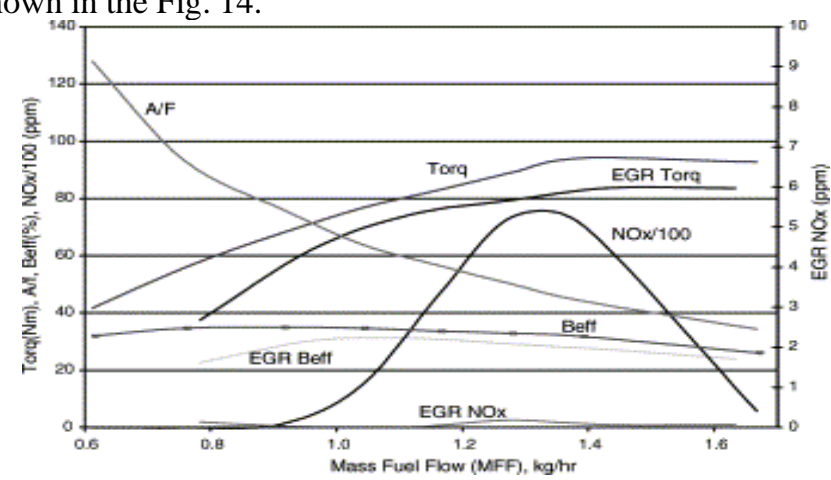

Fig. 14. Summary of engine operating parameters at $1500 \mathrm{rpm}$ for both EGR and lean burn strategy .

Verhelst [61] has devised technique to compensate the power output using supercharging in a single cylinder engine where the EGR methods have been used to limit the NOx emission. Similar model as in [56] has been developed by 
Kosmadakis [57] to compare the effect of EGR rate with the effect Lean burn fuel.

Yao et al. [4], [62] have studied the effect of EGR rate on NOx emission for different hydrogen flow rate ranging from $1.75 \mathrm{~kg} / \mathrm{h}$ to $2.79 \mathrm{~kg} / \mathrm{h}$. The results are shown in Fig. 15.

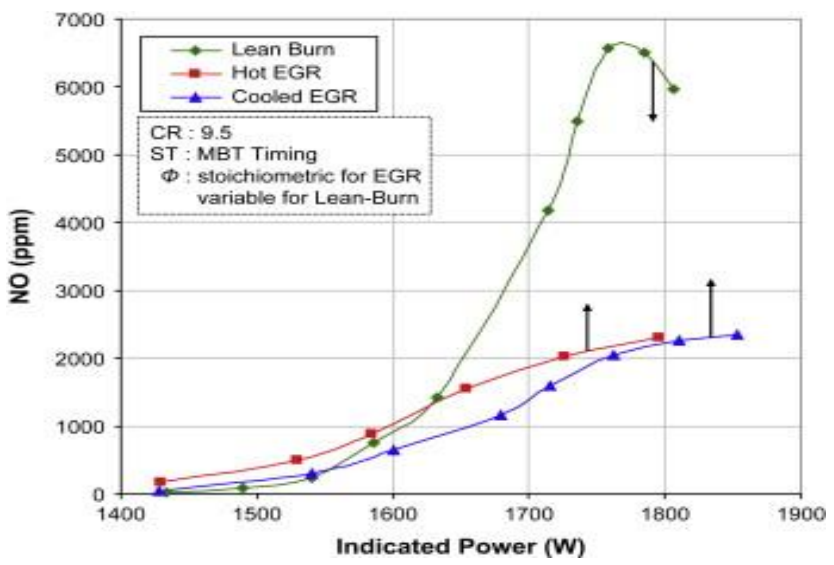

Fig. 15. Comparision of specific NOx emission for different power with different inlet supply such as lean burn, hot EGR, cooled EGR.

Vudumu et al. [63] have developed a computational model using PID (proportional integral and derivative) controller and $15 \mathrm{~mm}$ throttle valve to control the rate of EGR flow and have studied the variation of NOx emission with EGR rate and have compared the simulation value with the experimental data. They have observed that (Fig. 16), an approximate linear dependency between the EGR and NOx emission. They have also found a decrease of NOx emission from $7300 \mathrm{ppm}$ to 800 ppm when EGR rate is increased from 0 to 16 .

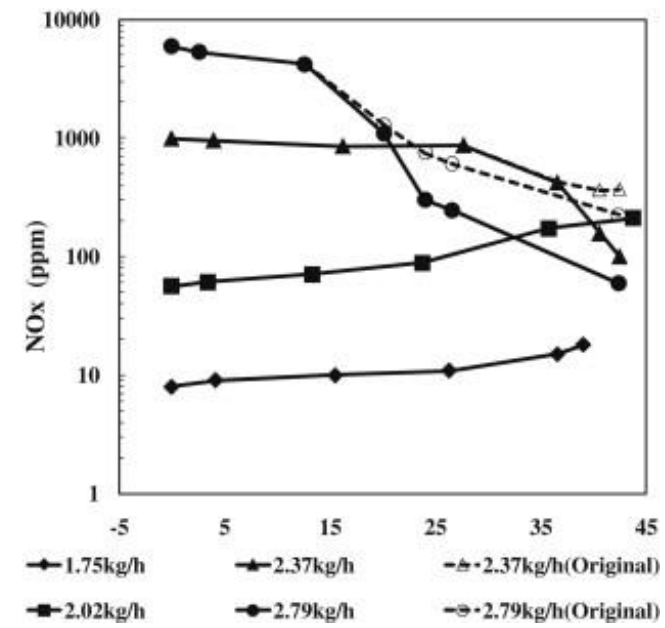

Fig. 16. Effect of EGR rate on NOx emission for different hydrogen flow rate.

\section{CONCLUSION}

This paper has presented a comprehensive review of both the theoretical work and experimental investigations made by various researchers on various aspects of NOx emission in hydrogen fueled IC engine. The summary of the present study is outlined as

1. Extended Zeldovic mechanism mainly predominates formation of NOx in a hydrogen operated IC engine, though other mechanisms like prompt NOx, intermediate $\mathrm{N}_{2} \mathrm{O}$ and $\mathrm{NNH}$ intermediate also cause the formation of NOx in IC engine.

2. An increasing trend in the NOx emission is observed to an equivalent ratio of 1.1 in the $\mathrm{H}_{2} \mathrm{IC}$ engine.

3. The spark timing of ignition is reported to be a possible solution to the NOx emission. It mainly reduces the period of ignition thus reduces the peak temperature in the cylinder.

4. Injection of water and different gases (hydrogen, helium, nitrogen) has been demonstrated to be an effective control of NOx emission. Water is found out to be more effective due to its high volumetric efficiency.

5. Use of EGR is noticed to be more effective than the conventional lean burn strategy to control the NOx emission. EGR used fuel gives more power output compared to the lean fuel for a limited amount of $\mathrm{NOx}$ emission.

\section{SCOPE OF FUTURE WORK}

Use of hydrogen as the fuel for the IC engine has the main limitation of NOx emission besides problem of back fire, misfire, knocking. The main objective of development of alternative fuel, that is reduction in the emission, without any significant reduction in power output and efficiency is yet to be achieved completely. There is a still long way to go to achieve this prime objective of reduction in emission without hampering the efficiency of the engine. Reduction of the overall NOx emission to almost zero by using the three-way catalytic converter will be the focus of future research. Different catalysts have been tested out to know its effect on the reduction of NOx emission. Recent research activities concentrate on emission control without reducing the power of hydrogen and diesel fueled IC engine with SCR and turbo charger used as accessories to control the emission and power output Simulation models and CFD models are also being developed by the researchers to predict and control the emission and performance of Hydrogen based IC engines.

\section{REFERENCES}

[1] Peter Hoffman, The Forever Fuel, the Story of Hydrogen. West View Press, Boulder, Colorado, 1981.

2] H Quadfleig, From Research to Market Application Experience on German Hydrogen Fuel Project. Int. Journal Hydrogen Energy, 13, 363 374, 1988.

[3] W. Cecil, On the application of hydrogen gas to produce a moving power in machinery; with a description of an engine which is moved by pressure of the atmosphere upon a vacuum caused by explosions of hydrogen gas and atmospheric air Transactions of the Cambridge Philosophical Society, 217-239, 1820.

[4] Zuo-yu, Fu-Shui Liu, Xing-hua Liu, Bai-gang Sun, Da-Wei Sun, Research and Development of Hydrogen Fuelled Engines in China. Int Journal Hydrogen Energy 37, 664-681, 2012

[5] L.M. Das, Rohit Gulati, P.K. Gupta, A Comparative Evaluation of performance characteristics of a spark ignition fuel hydrogen and Compressed Natural Gas as alternative fuels. Int. Journal Hydrogen Energy, 25, 783-793, 2000.

[6] H.s .Homan, A Experimental Study on Reciprocating Internal Combustion Engines Operated in Hydrogen. P.H.D. thesis, Cornell University, U.S.A. 1978.

[7] L.M. Das, Hydrogen Engines: A View of the Past and a Look into the Future, Int. Journal Hydrogen Energy, 15(6), 425-443, 1990.

[8] L.M. Das, Near-term Introduction of Hydrogen Engines for Automotive and Agricultural Application. Int. Journal Hydrogen Energy, 27, 479$487,2002$. 
[9] M.T. Chaichan, Q. A. Abass, Study of NOx Emission in SI Engine Fueled with Different kinds of Hydrocarbon Fuels and Hydrogen. AlKhwarizmi Engineering Journal, 6(2), 11-120, 2010.

$[10$

[11] Craig T. Bowman, Control of Combustion-Generated Nitrogen Oxide Emissions: Technology Driven by Regulation.24th symposium (International) on Combustion, 859-878, 1992.

[12] J. Miller, Craig T. Bowman, Mechanism and Modeling of Nitrogen Chemistry in Combustion. Prog. Energy Combust. Sci., 5, 287-338, 1989.

[13] S. R. Turns, an Introduction to Combustion Concepts and Applications. New York, NY: McGraw-Hill, Inc; 168-171, 2000.

[14] J. B. Heywood, Internal Combustion Engines Fundamentals. New York, NY: McGraw-Hill, Inc; 1988

[15] C.P. Fenimore, Formation of Nitric Oxide in Premixed Hydrocarbon Flames. 13th symposium (International) on Combustion, 13(1), 373-380, 1971.

[16] S.Verhelst, T.Wallner, Hydrogen-Fueled Internal Combustion Engines. Progress in Energy and Combustion Science, 35, 490-527, 2009.

17] D.Iverach, N. K. Kirov and B.S.Haynes, The Behavior of Nitrogen Species in Fuel Rich Hydrocarbon Flames, Combust. Sci. Technol., 15, 1103-1112, 1975

18] F.Bachmeier, K.H. Eberius, and Th. Just. The Formation of Nitric Oxide and the Detection of HCN in Premixed Hydrocarbon-Air Flames at 1 Atmosphere. Combust. Sci. Technol., 7, 771, 1973.

[19] A. N. Hayhurst, and I. M. Vince, Nitric Oxide Formation from N2 in Flames: The Importance of Prompt NO. Prog. Energy Combust. Sci., 266, 524-525, 1977.

[20] D Iverach, K. S. Basden, and N. Y.Kirov, Formation of Nitric Oxide in Fuel-lean and Fuel-rich Flames. $14^{\text {th }}$ symposium (International) on Combustion, 767-775,1973.

[21] J.Blauwens, B. Smets, and J.Peeters Mechanism of Promp NO Formation in Hydrocarbon Flames $16^{\text {th }}$ symposium (International) on Combustion, 1055-1064, The Combustion Institute Pittsburgh, 1977.

[22] T. Miyauchi, Y. Mori, A. Imamura, A Study of Nitric Oxide Formation in Fuel-Rich Hydrocarbon Flames: Role of Cyanide Species, $\mathrm{H}, \mathrm{OH}$ and $\mathrm{O}, 16^{\text {th }}$ symposium (International) on Combustion, 1073-1082, The Combustion Institute Pittsburgh, 1977.

[23] Y. Matsui, T. Nomaguchi, Spectroscopic Study of Prompt Nitrogen Oxide Formation Mechanism in Hydrocarbon-Air Flames Combust Flame, 32, 205, 1978.

[24] Y. Matsui and A. Yuuki, Radical Concentrations and Prompt NO Formation in Hydrocarbon-air Premixed Flames, Jap. J. Appl. Phys., 24, 598,1984

[25] R. A. Perry and C. F. Melius, The Rate and Mechanism of The Reaction of HCN with Oxygen Atoms over The Temperature Range 540-900 K. Proc. Combust. Inst., 20, 639-646, 1984.

26] J. W. Bozzelli and A. M. Dean, O + NNH: A possible New Route for NOx formation in flames Int. Journal of Chemical Kinetics, 27, 1097 $1109,1995$.

[27] Joel E Harrington, G.P. Smith, P.A. Berg, A.R. Noble, J.B. Jeffries, D.R Crosley, Evidence for A New NO Production Mechanism in Flames; $26^{\text {th }}$ symposium (International) on Combustion, 2133-2138, 1996.

[28] A.A. Konnov, G. Colson, J. De Ruyck, The New Route Forming NO Via NNH. Combustion and Flame, 121(3), 548-550, 2000.

[29] A.A Konnov, J De Ruycka, Temperature-Dependent Rate Constant for The Reaction $\mathrm{NNH}+\mathrm{O} \rightarrow \mathrm{NH}+\mathrm{NO}$. Combustion and Flame, 125(4) 1258-1264, 2001.

[30] M. Skottene, K. E. Rian, A Study of NOx Formation in Hydrogen Flames. Int. Journal of Hydrogen Energy, 32, 3572-3585, 2007.

[31] S.J. Klippensteina, L. B. Hardinga, P. Glarborgb, J. A. Miller, The Role of $\mathrm{NNH}$ in NO Formation and Control Combustion and Flame, 158(4), 774-789, 2011.

[32] T. Gatts, H. Li,C. Liew, S. Liu, T. Spencer, S. Wayne, N. Clark, An Experimental Investigation of $\mathrm{NO}_{2}$ Emission Characteristics of a Heavyduty $\mathrm{H}_{2}$-Diesel Dual Fuel Engine. Int. Journal of Hydrogen Energy, 35(20), 11349-11356, 2011.

33] V. Subramanian, J.M. Mallikarjuna and A.Ramesh, Effect of Water Injection and Spark Timing on the Nitric Oxide Emission and Combustion Parameters of a Hydrogen Fuelled Spark Ignition Engine, Int. Journal of Hydrogen Energy, 32, 1159-1173, 2006.

[34] H.S. Homan, P.C.T. de Boer, W.J. McLean Performance and Emissions of hydrogen Fueled Internal Combustion Engines. Int. Journal of Hydrogen Energy, 1, 153-172, 1983.
[35] L.M. Das, Exhaust Emission Characterization of Hydrogen-Operated Engine System: Nature of Pollutants and Their Control Techniques. Int Journal of Hydrogen Energy, 16(11), 765-775, 1991.

[36] T. Wallner, N. Matthias, and R. Scarcelli, Influence of Injection Strategy in a High-Efficiency Hydrogen Direct Injection Engine. SAE Int. J. Fuels Lubr., 5(1), 289-300, 2012.

[37] H.B. Mathur, P.R. Khajuria, Performance and Emission Characteristics of Hydrogen Fueled Spark Ignition Engine. Int. Journal of Hydrogen Energy, 9, 729-735, 1984

[38] L.M.Das, Hydrogen Engine: Research and Development (R\&D) Programmes in Indian Institute of Technology (IIT), Delhi Int. Journal of Hydrogen Energy, 27(9), 953-965,2002.

39] L.M.Das, Studies on Timed Manifold Injection in Hydrogen Operated Spark Ignition Engine: Performance, Combustion and Exhaust Emission Characteristics. Ph.D. Thesis, Indian Institute of Technology, Delhi, 1987.

[40] H.S. Homan, P.C.T. de Boer, W.J. McLean, The Effect of Fuel Injection on NOx Emissions and Undesirable Combustion for Hydrogen-Fuelled Piston Engines. Int. Journal of Hydrogen Energy, 8(2), 131-146, 1983.

[41] N.D. Glasson, R.K. Green, Performance of a Spark-Ignition Engine Fuelled with Hydrogen Using a High-Pressure Injector Int. Journal of Hydrogen Energy, 19(11), 917-923, 1994.

42] High-pressure hydrogen injection for internal combustion engines R.K. Green, N.D. Glasson Int. Journal of Hydrogen Energy, 17(11), 895-901, 1992.

[43] C.M. White R.R. Steeper, A.E. Lutz, The Hydrogen-Fueled Internal Combustion Engine: A Technical Review Int. Journal of Hydrogen Energy, 31(10), 1292-1305, 2006.

[44] H. Newhall, Combustion Process Fundamentals and Combustion Chamber Design for Low Emissions. SAE Technical Paper 751001 1975.

[45] P. N. Blumberg, Nitric Oxide Emissions from Stratified Charge Engines: Prediction and Control. Combustion Science and Technology, 8(1), 5-24, 1973.

[46] Alternative Control Techniques Document--NOx Emissions from Stationary Reciprocating Internal Combustion Engines. United states Environment Protection Agency, 1993.

47] Hailin Li, Ghazi A. Karim, Exhaust Emissions from an SI Engine Operating on Gaseous Fuel Mixtures Containing Hydrogen. Int. Journa of Hydrogen Energy 30, 1491-1499, 2005.

[48] A.R. Maher, S. Al-Baghdadi, Effect of Compression Ratio, Equivalence Ratio and Engine Speed on the Performance and Emission Characteristics of a Spark Ignition Engine Using Hydrogen as a Fue Renewable energy, 29, 2245-2260, 2004.

[49] L.M. Das, H B Mathur, T.N. Patro, Effects of Charge Diluents on the Emission Characteristics of Hydrogen Fueled Diesel Engine, Int. Journal of Hydrogen Energy, 17(8), 1992

[50] H.B. Mathur, L.M. Das, T.N. Patro, Hydrogen-fuelled Diesel Engine: Performance Improvement through charge dilution techniques. Int Journal of Hydrogen Energy, 18(5), 421-431, 1993.

[51] R. Adnan, H. H. Masjuki, T.M.I. Mahlia, Performance and Emission Analysis of Hydrogen Fueled Compression Ignition Engine with Variable Water Injection Timing. Energy, 43, 416-426, 2012.

[52] R.Lanzafame, Water Injection Effects in A Single Cylinder CFR Engine. SAE Technical Paper, 1999-01-0568, 1999.

[53] V. Subramanian, J.M. Mallikarjuna A. Ramesh, Effect of Water Injection and Spark Timing on the Nitric Oxide Emission and Combustion Parameters of a Hydrogen Fuelled Spark Ignition Engine. Int. Journal of Hydrogen Energy, 32, 1159-1173, 2007.

[54] A. Nande, T. Wallner and J. Naber, Influence of Water Injection on Performance and Emissions of a Direct-Injection Hydrogen Research Engine, SAE Technical Paper, 2008-01-2377, 2008.

55] A. Gadallah, , E. Elshenawy, A. Elzahaby, H. El-Salmawy, et al., Effect of In Cylinder Water Injection Strategies on Performance and Emission of a Hydrogen Fuelled Direct Injection Engine. SAE Technical Paper, 2009-01-1925,2009

[56] H. Safari, S.A. Jazayeri, R. Ebrahimi Potentials of NOx Emission Reduction Methods in SI Hydrogen Engines: Simulation Study, Int Journal of Hydrogen Energy, 34, 1015-1025, 2009

[57] G.M. Kosmadakis, C.D. Rakopoulos, J. Demuynck, M. De Paepe, S. Verhelst, CFD Modeling and Experimental Study Of Combustion and Nitric Oxide Emissions in Hydrogen-Fueled Spark-Ignition Engine Operating in a Very Wide Range of EGR Rates Int. Journal of Hydrogen Energy, 37, 10917-10934, 2012 
[58] A. Nande, S. Szwaja and J. Naber, Impact of EGR on Combustion Processes in Hydrogen Fuelled SI Engine. SAE Technical Paper, 200801-1039, 2008

[59] J. W. Heffel, NOx Emission and Performance Data for a Hydrogen Fueled Internal Combustion Engine at 1500rpm Using Exhaust Gas Recirculation. Int. Journal of Hydrogen Energy, 28, 901-908, 2003.

[60] J. W. Heffel, NOx Emission and Performance Data for a Hydrogen Fueled Internal Combustion Engine at 3000rpm Using Exhaust Gas Recirculation. Int. Journal of Hydrogen Energy, 28, 1285-1292, 2003.

[61] S. Verhelst, J. De Landtsheere, F. De Smet, C. Billiouw et al., Effects of Supercharging, EGR and Variable Valve Timing on Power and Emissions of Hydrogen Internal Combustion Engines. SAE Int. J. Engines, 2008-01-1033, 2008.

[62] H. Yao, , B. Sun, H. Tian, Q. Luo et al., A Study of Hydrogen Internal Combustion Engine EGR System, SAE Technical Paper, 2014-01-1071, 2014 ,

[63] S. K. Vudumu, U.O. Koylu, Computational Modeling, Validation, and Utilization for Predicting the Performance, Combustion and Emission Characteristics of Hydrogen IC engines, energy, 36, 647-655, 2011.

[64] Ma Fan-hua,Liu Hai-quan, Li Yong, Wang Yu, Zhao Shu-li, Analysis of In-Cylinder Combustion of Hydrogen Fueled Engine Chinese Internal Combustion Engine Engineering , 29(1), 29-33, 2008.

[65] International Statistics of Environment study at Nation Master.com World Values Survey, 2005.

[66] SCAQMD, Annual RECLAIM Audit Report for the 2004 Compliance Year. South Coast Air Quality Management District, 2006. 